\title{
Clinical Governance
}

\section{Sathiadas. $M G$}

Email: docsathiadas@hotmail.com

https://orcid.org/0000-0002-7822-0447

Clinical governance is defined as a system thro -ugh which an organisation is accountable for continuously improving the quality of their services and safeguarding high standards of care by creating an environment in which excellence in clinical care can be enhanced. This also includes the responsibility of financial accountability and a requirement to operate within the limits of its resources. (1) Clinical governance becomes effective when it reaches every level of a healthcare organisation. It requires structures and processes that integrate financial control, service performance, and clinical quality in ways that will engage clinicians and generate service improvements. (2)

Clinical governance becomes successful when clinicians remain central in the decision making process of the individual patient in the best interest, using the available resources, should address all aspects rather than dealing with risk, safety, quality and all proceedings and discussions regarding governance are open and transparent. (3)

Literature review and expert opinion has identified six pillars for effective clinical governance. They are clinical effectiveness, quality assurance, provider education and development, clinical audits, risk management, research and development. (4)

One of the biggest problems in many healthcare systems is the gulf between the front line clinical staff and policymakers and managers. In health care, however, the hierarchy is often disconnected, resulting in two separate discussions- one for policy makers, managers, and politicians about their aspirations and interests and a second for clinicians about their work. Both are legitimate, but problems arise because these two fail to connect or interact amicably. (2)

Every clinician in view of effective clinical governance should question him/herself regarding the care of each condition in the aspects of "are we doing the right things? Considering the existing resource constraints, are we delivering value for money?" For common conditions, how appropriate and effective are the services we offer? Are we doing things right? Are we managing clinical performance according to national codes of clinical practice? For common conditions, how systematised are our care processes and how are we performing on risk, safety, quality, patient evaluation, and clinical outcomes? Are we keeping up with new developments and what are we doing to extend our capacity to undertake clinical work in these areas? What strategies are in place for professional development for each condition? What are we doing about clinical mentoring, leadership development, and staff appraisal and review? These questions and discussion should take place at every level from clinical to the managerial staff, so that the governance becomes productive.

In addition to having good systems for education, training and continuing professional development it is important to have an effective system for risk management. It should be to identify what can and does go wrong during care, understand the factors that influence this, learning lessons from any adverse events, ensure action is taken to prevent recurrence and having systems in place to reduce risks. (5)

The aims of good governance should be to raise patient satisfaction, improve collaborative relationships and efficiency within and across clinical teams, increase job satisfaction for professionals, improve clinical outcome and reduce significant events.

"Management is about running the business, governance is about seeing it run properly" Adrian, A (2000)

\section{References:}

1. Scally G, Donaldson LJ. Looking forward: clinical governance and the drive for quality improvement in the new NHS in England. BMJ 1998;317: 61-5. 
2. Nigel Edwards, Model could work, BMJ 2004; 329:681-682 doi: https://doi. org/10.1136/bmj.329.7467.681

3. Pieter J Degeling, Sharyn Maxwell, Rick ledema, David J Hunter; Making clinical governance work, BMJ. 2004 Sep 18;
329(7467): 679-681. doi: 10.1136/ bmj.329.7467.679

4. Gray A, Harrison S, eds. governing medicine: theory and practice. Buckingham: Open University Press, 2004

5. https://www.uhb.nhs.uk/clinicalgovernance-components.htm 